DOI: $10.526 /$ cab.v14i3.16404

\title{
INCLUSÃO DE DIFERENTES FONTES DE AMIDO NA DIETA DE JUNDIÁS (Rhamdia quelen): PARÂMETROS METABÓLICOS E BIOQUÍMICOS
}

\author{
Naglezi de Menezes Lovatto ${ }^{1}$, Fernanda Rodrigues Goulart ${ }^{1}$, Viviani Correia ${ }^{1}$, Cristiano Costenaro \\ FERREIRA $^{2}$, LEILA PICOLLI DA SILVA ${ }^{3}$, JOÃO RADÜNZ NETO ${ }^{3}$ \\ ${ }^{1}$ Pós-graduandas da Universidade Federal de Santa Maria, Santa Maria, RS, Brasil. naglezilovatto@hotmail.com \\ ${ }^{2}$ Pós graduando da Universidade Federal de Pelotas, Pelotas, RS, Brasil. \\ ${ }^{3}$ Professores Doutores da Universidade Federal de Santa Maria, Santa Maria, RS, Brasil.
}

O presente estudo foi conduzido com o objetivo de avaliar a influência da ingestão de diferentes fontes de amido sobre indicadores metabólicos e enzimáticos em sangue e fígado de jundiás. $\mathrm{O}$ experimento foi realizado durante 20 dias, em sistema de recirculação de água. Foram utilizados 60 peixes (peso médio inicial de $60 \pm 4 \mathrm{~g}$ ), divididos em três tratamentos, compostos por dietas com inclusão de aveia descascada; farelo de arroz desengordurado e uma dieta controle, todas com $37 \% \mathrm{~PB}$ e $3200 \mathrm{Kcal}$ ED/Kg. Não houve diferença significativa para os parâmetros de crescimento. As análises hepáticas demonstraram redução no teor de glicogênio para o tratamento que continha aveia; no entanto, sem alterações aparentes na atividade das enzimas alanina-aminotransferase e glicose-6fosfatase. Quanto às análises sanguíneas, não foram observadas diferenças significativas nas determinações de colesterol total, colesterol HDL e albumina, porém, os níveis séricos de proteínas totais foram maiores para o tratamento com farelo de arroz desengordurado e os níveis de triglicerídeos foram menores nos animais que receberam dieta contendo aveia como fonte amídica. Pode-se concluir que o jundiá é capaz de metabolizar diferentes fontes de carboidrato, sem a necessidade de utilizar a proteína, tanto da dieta quanto a corporal, como fonte de energia.

PALAVRAS-CHAVE: carboidrato; metabolismo intermediário; nutrição de peixes.

\section{INCLUSION OF DIFFERENT SOURCES OF STARCH IN DIET FOR JUNDIÁ (Rhamdia quelen): METABOLIC AND BIOCHEMICAL PARAMETERS}

\section{ABSTRACT}

This study was conducted to evaluate the influence of ingestion of different sources of starch on enzymatic and metabolic indicators in blood and liver of Rhamdia quelen. The experiment was conducted during 20 days in water recirculation system. Sixty fishes (initial average weight $60 \mathrm{~g}$ ) were used and divided into three treatments composed of the following diets: inclusion of peeled oats, defatted rice bran and control diet, all with $36 \%$ crude protein and 3,200 Kcal DE/Kg. There was no significant difference in growth parameters. The analysis demonstrated a reduction in liver glycogen content for the treatment with oats; however, no apparent changes in the activity of the enzymes alanine-aminotransferase and glucose-6-phosphatase were observed, raising the possibility that the fishes did not use gluconeogenesis. The blood analysis, showed no significant differences in the determinations of total cholesterol, HDL cholesterol and albumin; however, serum levels of total protein were higher for treatment with defatted rice bran, and triglyceride levels were lower in animals that received diet containing oat as starch source. It can be concluded that Rhamdia quelen is able to metabolize various sources of carbohydrate, without the need to use either diet or body protein as an energy source.

KEYWORDS: carbohydrate; fish nutrition; intermediary metabolism. 


\section{INTRODUÇÃO}

Minimizar a quantidade de proteína da dieta e atender as exigências de energia usando carboidratos e lipídios é um dos principais objetivos da nutrição de peixes (FERNÁNDEZ et al., 2007). No entanto, é sabido que as espécies diferem grandemente na sua capacidade de digerir carboidratos, o que está relacionado às diferenças anatômicas e funcionais do trato gastrointestinal e órgãos associados. Os peixes onívoros e herbívoros possuem maior capacidade de aproveitamento dos carboidratos em comparação aos carnívoros, além disso, as espécies onívoras tendem a superar os carnívoros em termos de utilização de alimento, economia de proteína e estímulo do crescimento (HEMRE et al., 2002; KROGDAHL et al., 2005).

Por esse motivo, algumas espécies nativas, tais como o jundiá (Rhamdia quelen), tem sido intensamente estudadas quanto ao seu potencial de adaptação a manejo criatório intensivo. Seu hábito alimentar onívoro favorece o arraçoamento, devido a sua melhor adaptação a diferentes tipos de alimentos. Essa espécie tem despertado grande interesse dos piscicultores da região Sul do Brasil, devido a seu rápido crescimento e resistência ao manejo, mesmo nos meses de inverno do Sul (BARCELLOS et al., 2003), além da resistência ao estresse, reprodução viável em cativeiro (SALHI et al., 2004) e capacidade de digerir ração seca na primeira alimentação (FRACALOSSI et al., 2002).

Os carboidratos são fontes energéticas de baixo custo que podem ser utilizadas em dietas; no entanto, sua eficiência no efeito poupador de proteína nos peixes pode variar influenciada por fatores como hábito alimentar (SHIAU, 1997), espécie cultivada e tipo e quantidade de carboidrato (HEMRE et al., 2002; KROGDAHL et al., 2005). Alguns estudos indicam que o jundiá possui limitações quanto à digestão de fontes amídicas, o que onera o custo das formulações. Em contraste, outros estudos desenvolvidos recentemente demonstram que há uma resposta positiva entre a presença de carboidratos na dieta com a produção de enzimas amilolíticas digestivas, o que reflete em diferentes respostas no metabolismo intermediário (PEDRON, 2010).

As informações escassas e conflitantes sobre o uso do amido na nutrição de jundiá motivam a condução de novos pesquisas a fim de entender melhor o metabolismo desse nutriente energético. Considerando esse fato, o presente estudo foi conduzido com o objetivo de avaliar indicadores metabólicos e enzimáticos no sangue e no fígado de jundiás adultos alimentados com diferentes fontes de amido na dieta.

\section{MATERIAL E MÉTODOS}

O trabalho foi realizado no Laboratório de Piscicultura, Departamento de Zootecnia da Universidade Federal de Santa Maria (altitude $95 \mathrm{~m}$, $\left.29^{\circ} 43^{\prime} \mathrm{S}, 53^{\circ} 42^{\prime} \mathrm{W}\right)$. Esta pesquisa faz parte de um projeto maior, denominado densidade de estocagem e fontes energéticas vegetais para jundiá e carpa húngara criados em bicultivo., protocolado sob o número 23081.006971/2009-52, no Comitê de Ética. O procedimento experimental foi realizado no período de 20 de outubro a 20 de novembro de 2009, sendo utilizados 10 dias de adaptação às dietas e ao novo ambiente. $\mathrm{O}$ experimento teve duração de 20 dias, utilizando-se sistema fechado de recirculação de água com dois filtros biológicos, reservatório principal $(2000$ L) dotado de aquecimento (resistências - $2000 \mathrm{~W}$ ) e três caixas de polipropileno com volume útil de $280 \mathrm{~L}$, com entrada e saída de água individual e sistema de aeração.

Os parâmetros da água temperatura e oxigênio dissolvido $\left(\mathrm{mg}^{\mathrm{d}} \mathrm{dL}^{-1}\right)$ foram monitorados por análises diárias utilizando oxímetro digital YSI modelo 550A. Semanalmente foi analisada a dureza da água (mg $\mathrm{CaCO}_{3} \mathrm{~L}^{-1}$ ) segundo metodologia descrita por ADAD (1982), sendo que as amostras analisadas foram coletadas junto aos filtros biológicos do circuito.

Três dietas experimentais compuseram os tratamentos (Tabela 1), sendo uma com inclusão de aveia descascada, outra com farelo de arroz desengordurado estabilizado (FADE) e uma dieta controle (farelo de trigo + milho). Essas rações foram elaboradas no Laboratório de Piscicultura (UFSM) da seguinte maneira: os ingredientes secos (moídos e pesados) foram homogeneizados em misturador elétrico seguido de adição de óleo e água até obtenção de uma massa homogênea. As dietas foram peletizadas em máquina de moer carne, secas em estufa $\left(50^{\circ} \mathrm{C}\right)$ por 24 horas, depois trituradas, embaladas em sacos plásticos, identificadas e armazenadas em freezer $\left(-18^{\circ} \mathrm{C}\right)$. As dietas foram isocalóricas e isoproteicas, com $37 \%$ PB e 3200 Kcal. $\mathrm{kg}^{-1}$ de Energia Digestível calculada. Os tratamentos foram os seguintes: controle - dieta basal com milho moído (14,5\%); aveia - aveia descascada (20\%); FADE - farelo de arroz desengordurado estabilizado (20\%).

Foram utilizados 20 animais por tratamento, sendo cada animal considerado uma repetição, totalizando 60 animais experimentais, com peso médio inicial de $60 \pm 4 \mathrm{~g}$, arraçoados duas vezes ao dia (às $8 \mathrm{~h} 00 \mathrm{~m}$ e $16 \mathrm{~h} 00 \mathrm{~min}$ ), até a saciedade aparente. Uma hora após a oferta do alimento foi realizada limpeza (sifonagem) dos tanques, para retirada de fezes e eventuais sobras de alimento.

Decorrido o período experimental, sete animais de cada tratamento foram capturados 
aleatoriamente e anestesiados para obtenção do peso final $(\mathrm{g})$, comprimento total $(\mathrm{cm})$ e comprimento padrão $(\mathrm{cm})$. Para a coleta de sangue, utilizaram-se seringas descartáveis com heparina ou sem anticoagulante, conforme exigências analíticas posteriores. Foram realizadas as seguintes análises hematimétricas: glicose $\left(\mathrm{mg} . \mathrm{dL}^{-1}\right)$, triglicerídeos $\left(\mathrm{mg} \cdot \mathrm{dL}^{-1}\right)$, colesterol total $\left(\mathrm{mg} \cdot \mathrm{dL}^{-1}\right)$ e colesterol HDL $\left(\mathrm{mg}^{\mathrm{d} \mathrm{dL}^{-1}}\right)$, todos no plasma; e proteínas totais (g.dL $\left.{ }^{-1}\right)$ e albumina $\left(\mathrm{g} . \mathrm{dL}^{-1}\right)$ no soro, através de kits comerciais da marca Doles.

Após a coleta de sangue, os animais foram eutanasiados em água com gelo (1:1) para remoção do tecido hepático a fim de quantificar o conteúdo de glicogênio ( $\mu \mathrm{mol}$ glicose liberada $\mathrm{g}^{-1}$ tecido), segundo método descrito por BIDINOTTO et al. (1998), a atividade das enzimas alanina aminotransferase (U.I.L ${ }^{-1}$ ), através de kit comercial Doles ${ }^{\circledR}$ e glicose-6-fosfatase hepática $(\mathrm{nmol} / \mathrm{h} / \mathrm{mg}$ proteína), conforme BERGMEYER (1965).

$\mathrm{O}$ delineamento experimental foi inteiramente casualizado, com três tratamentos e vinte repetições. Os resultados foram submetidos à análise univariada de variância e as médias foram comparadas pelo teste de Duncan em nível de 5\% de significância. Todas as análises estatísticas foram realizadas usando-se o programa estatístico SPSS 8.0 .

Tabela 1. Composição das dietas experimentais de jundiás alimentados com diferentes fontes de amido

\begin{tabular}{|c|c|c|c|}
\hline \multicolumn{4}{|c|}{ TRATAMENTOS } \\
\hline Ingredientes & CONTROLE & $\mathrm{AD}^{2}$ & $\mathrm{FADE}^{3}$ \\
\hline Farelo de soja & 33 & 23 & 15,5 \\
\hline Farinha de carne e ossos suína & 29,5 & 32,8 & 32,4 \\
\hline Farelo de trigo & 15,5 & 8,5 & 0 \\
\hline Milho moído (grãos) & 14,5 & 0 & 6,0 \\
\hline Aveia descascada & -- & 20 & -- \\
\hline Farelo e arroz desengordurado & -- & -- & 20 \\
\hline Óleo de soja & 4,0 & 4,3 & 7,7 \\
\hline Mistura vitamínica e mineral $^{1}$ & 2,0 & 2,0 & 2,0 \\
\hline Calcário & 0,5 & 0,5 & 1,0 \\
\hline Cloreto de Sódio & 1,0 & 0,5 & 0,5 \\
\hline Cloreto de colina & -- & 1,0 & 1,0 \\
\hline SPC $60^{4}$ & -- & 7,3 & 14,0 \\
\hline Total & 100 & 100 & 100 \\
\hline \multicolumn{4}{|l|}{ Composição (\% da dieta) } \\
\hline PB & 36,92 & 37,51 & 37,45 \\
\hline $\mathrm{ED}(\mathrm{Kcal} / \mathrm{Kg})^{8}$ & 3216,70 & 3291,79 & 3253,53 \\
\hline Lisina & 1,66 & 1,56 & 1,42 \\
\hline Metionina & 0,47 & 0,48 & 0,48 \\
\hline Treonina & 1,35 & 1,42 & 1,41 \\
\hline Triptofano & 0,66 & 0,63 & 0,57 \\
\hline Valina & 1,45 & 1,46 & 1,36 \\
\hline Isoleucina & 1,30 & 1,30 & 1,17 \\
\hline Leucina & 2,19 & 2,17 & 1,93 \\
\hline Fenilalanina & 1,38 & 1,50 & 1,46 \\
\hline Cálcio $^{5}$ & 2,54 & 2,28 & 2,58 \\
\hline Fósforo $^{5}$ & 1,58 & 1,45 & 1,83 \\
\hline Fibra em detergente neutro ${ }^{6}$ & 20,41 & 17,38 & 19,50 \\
\hline Amido disponível ${ }^{7}$ & 10,40 & 15,63 & 10,22 \\
\hline Extrato etéreo ${ }^{7}$ & 14,64 & 13.04 & 14,22 \\
\hline
\end{tabular}

${ }^{1}$ Composição da mistura vitamínica e mineral (Mig Fish 1\% de inclusão/Mig Plus ${ }^{\circledR}$ ): Ác. Fólico: 300mg; Ác. Pantotênico: 3000mg; Ác. Glutâmico: 1mg; Cobalto: 60mg; Cobre: 1000mg; Colina: $102120 \mathrm{mg}$; Ferro: 5000mg; Biotina: $60 \mathrm{mcg}$; Iodo: 45mg; Manganês: 8000mg; Magnésio: 5\%; Selênio: 60mg; Vit.A: 1000UI; Vit. B1: 1500mg; Vit. B2: 1500mg; Vit. B6: 1500mg; Vit. B12: 2000mcg; Vit. C: $15000 \mathrm{mg}$; Vit. D: 240 UI; Vit. E: $10000 \mathrm{mg}$; Vit. K: $400 \mathrm{mg}$; Zinco: 14000mg; Inositol $10000 \mathrm{mg}$; Niacina $9000 \mathrm{mg}$; antioxidante: $792 \mathrm{mg} ;{ }^{2} \mathrm{AD}$ : Aveia Descascada; ${ }^{3} \mathrm{FAD}$ : Farelo de Arroz Desengordurado; ${ }^{4}$ SPC60: concentrado proteico de soja $60 \%$; ${ }^{5}$ Analisada: Nutron Alimentos LTDA; ${ }^{6}$ Analisados - Laboratório de Bromatologia e Nutrição de Ruminantes - DZ/UFSM. ${ }^{7}$ Analisado- Laboratório de Piscicultura (UFSM). ${ }^{8}$ Calculada: Energia digestível $=\left[\left(\mathrm{PB}^{*} 5640 \mathrm{Kcal} / \mathrm{Kg} * 0,85\right)+(\mathrm{EE} * 9440 \mathrm{Kcal} / \mathrm{Kg}\right.$ $\left.* 0,9)+\left(\mathrm{CSDN}^{*} 4110 \mathrm{Kcal} / \mathrm{Kg} * 0,60\right)\right]$ (Meyer et al., 2004). 


\section{RESULTADOS E DISCUSSÃO}

No decorrer do período experimental, os parâmetros físicos e químicos médios da água ficaram dentro dos níveis aceitáveis para a espécie de acordo com a biologia do jundiá (GOMES et al., 2000): 24,5 ${ }^{\circ} \mathrm{C}$ de temperatura; $6,2 \mathrm{mg} \cdot \mathrm{dL}^{-1}$ de oxigênio dissolvido e $52 \mathrm{mg} \mathrm{CaCO} 3 . \mathrm{L}^{-1}$ de dureza.

Ao final do período experimental, os jundiás não apresentaram diferença significativa $(P<0,05)$ para as variáveis de desempenho (Tabela 2 ), indicando que as duas fontes energético-amídicas testadas (Aveia e FADE), podem ser utilizadas na dieta de jundiás sem comprometer os parâmetros de crescimento. Trabalhando com larvas de tilápia-do-nilo (Oreochromis niloticus) alimentadas com dietas contendo até $10 \%$ de amido, BOSCOLO et al. (2008) observaram que as mesmas não apresentaram alterações significativas para as variáveis peso final, ganho de peso, fator de condição e sobrevivência. RAWLES \& LOCHMANN (2003) estudaram os efeitos da relação amilopectina/amilose do amido de milho no crescimento, composição corporal e resposta glicêmica em alevinos híbridos de "sunshine bass" (Morone chrysops $x$ M. saxatilis). Os autores observaram que a utilização de dietas formuladas com amido contendo maior proporção de amilose $(30 \% / 70 \%)$ melhorou a utilização dos carboidratos, com maior ganho em peso.

WILSON (1994) relatou que os carboidratos da dieta são nutrientes lentamente digeridos, o que pode gerar respostas glicêmicas estáveis e melhor crescimento. No entanto, RAWLES \& LOCHHMANN (2003) advertiram que a melhora no ganho em peso (incremento da massa corporal e diminuição da gordura visceral) é item difícil de conseguir quando os peixes são alimentados com elevadas quantidades de carboidratos na dieta.

Tabela 2.Valores de peso final, comprimento total e comprimento padrão de jundiás alimentados com amido de diferentes fontes de carboidratos

\begin{tabular}{lccccc}
\hline Parâmetros & \multicolumn{5}{c}{ TRATAMENTOS } \\
\hline & Controle & Aveia & FADE & CV & P \\
\cline { 2 - 6 } Peso final $(\mathrm{g})$ & $80,11 \pm 8,50$ & $83,28 \pm 9,46$ & $86,97 \pm 8,46$ & 11,27 & $\mathrm{~ns}$ \\
Comprimento total $(\mathrm{cm})$ & $20,37 \pm 1,77$ & $20,02 \pm 1,08$ & $20,10 \pm 0,51$ & 5,54 & $\mathrm{~ns}$ \\
Comprimento padrão $(\mathrm{cm})$ & $16,44 \pm 0,70$ & $16,43 \pm 0,80$ & $16,47 \pm 0,37$ & 3,79 & $\mathrm{~ns}$ \\
\hline
\end{tabular}

Valores expressos como média \pm desvio padrão. Médias com letras diferentes, na linha, apresentam diferença significativa pelo teste de Duncan $(\mathrm{P}<0,05) \mathrm{CV}$ : coeficiente de variação; ns= não significativo $(\mathrm{P}>0,05) ;{ }^{*} \mathrm{p}<0,05$.

Tabela 3. Efeito dos tratamentos sobre parâmetros metabólicos e bioquímicos de jundiás alimentados com diferentes fontes de carboidratos

\begin{tabular}{lccccc}
\hline Parâmetros & \multicolumn{5}{c}{ TRATAMENTOS } \\
\hline & Controle & Aveia & FADE & CV & P \\
\cline { 2 - 6 } Glicogênio & $239,81 \pm 93,02^{\mathrm{a}}$ & $140,36 \pm 41,63^{\mathrm{b}}$ & $166,31 \pm 62,74^{\text {ab }}$ & 24,44 & $*$ \\
G-6-Pase & $1,36 \pm 0,32$ & $1,36 \pm 0,22$ & $1,10 \pm 0,14$ & 15,37 & $\mathrm{~ns}$ \\
ALT & $763,37 \pm 94,34$ & $474,03 \pm 244,54$ & $511,58 \pm 102,15$ & 34,38 & ns \\
\hline
\end{tabular}

Glicogênio: $\mu \mathrm{mol}$ glicose liberada /g tecido; G-6-Pase (Glicose 6-fosfatase): nmol/h/mg proteína; ALT: alanina aminotransferase (U.I./L). Valores expressos como média \pm desvio padrão. Médias com letras diferentes, na linha, apresentam diferença significativa pelo teste de Duncan $(\mathrm{P}<0,05)$; CV: coeficiente de variação; ns= não significativo $(\mathrm{P}>0,05) ;{ }^{*} \mathrm{p}<0,05$.

As medidas hepáticas (Tabela 3) indicaram redução significativa $(\mathrm{P}<0,05)$ no teor de glicogênio entre os tratamentos FADE e Aveia em relação ao controle, sugerindo a ocorrência de glicogenólise, já que nestes mesmos tratamentos foram encontrados os maiores valores de glicose circulante (Tabela 4); entretanto, não ocorreu alteração significativa $(\mathrm{P}>0,05)$ na atividade da enzima glicose-6-fosfatase, descartando-se a ocorrência de gliconeogênese. Igualmente, a atividade da enzima alanina aminotransferase no fígado não apresentou diferença significativa $(\mathrm{P}>0,05)$ entre as dietas testadas. FERNÁNDEZ et al. (2007), por outro lado, estudaram o efeito da substituição da proteína da dieta por milho gelatinizado em alevinos de Sparus aurata L., encontrando alta correlação entre o nível de carboidrato na dieta com atividade da enzima alanina aminotransferase, ou seja, a atividade dessa enzima foi maior no grupo que recebeu menor conteúdo de carboidrato na dieta.

Para SÁNCHEZ-MUROS (1998), o aumento da atividade da enzima alanina aminotransferase (ALT), envolvida na síntese proteica, pode estar associada à produção de massa muscular bem como à utilização de proteína como fonte de energia. No entanto, a atividade da glicose-6-fosfatase observada no presente estudo descarta o efeito de tratamentos para esse segundo evento metabólico relatado.

Neste trabalho não foram observadas 
diferenças $(\mathrm{P}>0,05)$ nas determinações sanguíneas para colesterol total, colesterol HDL e albumina (Tabela 4), sugerindo que as diferentes fontes de carboidratos não interferiram nas concentrações normais dessas variáveis. Contudo, CORRÊIA (2010) observou menores níveis séricos de colesterol total para juvenis de jundiá alimentados com aveia descascada e FADE em relação ao tratamento controle. Além disso, os valores de colesterol total encontrados pelo autor foram superiores aos do presente estudo, o que pode estar relacionado com a idade dos animais.

Os jundiás alimentados com os tratamentos Controle e FADE apresentaram os maiores níveis séricos de triglicerídeos e os menores níveis foram detectados na dieta com aveia (Tabela 4), estando de acordo com os resultados encontrados por CORRÊIA et al. (2009). SILVA et al. (2003) encontraram resultados semelhantes, sugerindo que a diminuição observada de triglicerídeos ocorreu pelo fato de fibras solúveis contidas na aveia provocarem retardo no esvaziamento gástrico, o que pode levar a uma diminuição nos níveis de triacilglicerol.

Os maiores teores de proteínas totais circulantes foram observados nos animais submetidos ao tratamento $\operatorname{FADE}(4,63 \pm 0,33)$, mas não a maior atividade da enzima alanina aminotransferase. Esse fato sugere a utilização da proteína da dieta, sem necessidade de desaminação e transaminação de proteína tecidual como fonte energética (MELO et al., 2006).

Sugere-se que a utilização de carboidratos na nutrição de peixes pode reduzir o catabolismo de proteínas para síntese de glicose, ou seja, promove efeito poupador de proteína. Além disso, pode diminuir os desperdícios de nitrogênio no ambiente, bem como o próprio desperdício de alimento e a baixa produção de pescado, os quais, segundo MELO et al. (2006), podem ser evitados através da análise de parâmetros fisiológicos e bioquímicos da digestão e avaliação do metabolismo dos peixes.

Com isso consegue-se aperfeiçoar o uso de energia durante o processo de metabolização dos nutrientes. Além disso, estudos envolvendo análise de metabólitos e atividades enzimáticas podem ser utilizadas como indicadores do estado nutricional e crescimento do peixe (MELO, 2004).

Tabela 4. Parâmetros metabólicos em soro e plasma de jundiás alimentados com diferentes fontes de amido

\begin{tabular}{lccccc}
\hline Parâmetros & \multicolumn{5}{c}{ TRATAMENTOS } \\
\hline Plasma & Controle & Aveia & FADE & CV & P \\
\hline Glicose & $47,38 \pm 9,97^{\mathrm{b}}$ & $78,10 \pm 18,53^{\mathrm{a}}$ & $72,9 \pm 16,11^{\mathrm{a}}$ & 20,69 & $*$ \\
Triglicerídeos & $573,31 \pm 156,27^{\mathrm{a}}$ & $229,55 \pm 42,09^{\mathrm{b}}$ & $563,98 \pm 204,89^{\mathrm{a}}$ & 27,58 & $*$ \\
Colesterol total & $148,43 \pm 12,62$ & $146,12 \pm 14,68$ & $160,63 \pm 19,42$ & 9,93 & $\mathrm{~ns}$ \\
Colesterol HDL & $59,65 \pm 9,27$ & $45,74 \pm 4,11$ & $57,35 \pm 12,99$ & 10,40 & $\mathrm{~ns}$ \\
\hline Soro & & & & \\
\hline Proteínas totais & $3,98 \pm 0,28^{\mathrm{b}}$ & $4,13 \pm 0,20^{\mathrm{b}}$ & $4,63 \pm 0,33^{\mathrm{a}}$ & 6,93 & $\mathrm{~ns}$ \\
Albumina & $1,22 \pm 0,13$ & $1,09 \pm 0,17$ & $1,16 \pm 0,19$ & 14,21 & $\mathrm{~ns}$ \\
\hline
\end{tabular}

Glicose: mg/dL; Triglicerídeos: mg/dL; Colesterol: mg/dL; Colesterol HDL: mg/dL; Proteinas totais: g/dL; albumina: g/dL; Valores expressos como média \pm desvio padrão. Médias com letras diferentes, na linha, apresentam diferença significativa pelo teste de Duncan $(\mathrm{P}<0,05)$. CV: coeficiente de variação; ns= não significativo $(\mathrm{P}>0,05) ;{ }^{*} \mathrm{p}<0,05$

\section{CONCLUSÕES:}

Pode-se concluir que o jundiá é capaz de metabolizar diferentes fontes de carboidrato, sem a necessidade de utilizar a proteína, tanto da dieta, quanto corporal, como fonte de energia.

O fato de a atividade da enzima glicose-6fosfatase não ter sido alterada sugere que os peixes não utilizaram gliconeogênese para formar glicose, podendo ter aproveitado de maneira eficiente as fontes de glicose fornecidas nas dietas.

Independente da origem e das proporções entre as frações amidolíticas, as fontes de amido utilizadas no presente trabalho não comprometem o crescimento nem o metabolismo intermediário dos peixes.

\section{REFERÊNCIAS}

ADAD, J.M.T., Controle químico de qualidade da água. Guanabara Press, Rio de Janeiro. 203p, 1982.

BARCELLOS, L.J.G., KREUTZ, L.C., RODRIGUES, L.B., FIOREZE, I., QUEVEDO, R.M., CERICATO, L.,CONRAD, J., SOSO, A.B., FAGUNDES, M., LACERDA, L.A., TERRA, S. Haematological and biochemical characteristics of male jundia' (Rhamdia quelen Quoy \& Gaimard Pimelodidae): changes after acute stress, Aquaculture Research, v. 34, p. 1465-1469, 2003. 
BERGMEYER, H.U. Methods in enzymatic analysis. New York, San Francisco, London, Verlag Chemie Weinheim, Academic Press Inc, 1965.

BIDINOTTO, P.M.; SOUZA, R.H.S.; MORAES, G. Hepatic glycogen in eight tropical freshwater teleost fish: A procedure for field determinations of microsamples. Boletim Técnico CEPTA, v.10, p.53-60, 1997.

BOSCOLO, W. R.; Signor, A.; Signor, A.A.; Feiden, A.; Reidel, A. Inclusão de amido em dietas para larvas de tilápia-do-nilo. Revista Brasileira de Zootecnia, v.37, n.2, p.177-180, 2008.

CORRÊIA, V. Densidade de estocagem e fontes energéticas vegetais no cultivo intensivo de jundiá e carpa húngara. (Dissertação de Mestrado). Universidade Federal de Santa Maria, 73p, 2010, disponível em: $<$ http://w3.ufsm.br/ppgz/conteudo/Defesas/Dissertacoes/V ivianiCorreia.pdf > . Acesso em: março de 2011.

FERNÁNDEZ, F.; MIGUEL, A.G.; CÓRDOBA, M.; VARAS, M.; METÓN, I.; CASERAS, A.; BAANANTE, I.V. Effects of diets with distinct protein-to-carbohydrate ratios on nutrient digestibility, growth performance, body composition and liver intermediary enzyme activities in gilthead sea bream (Sparus aurata,L.) fingerlings. Journal of Experimental Marine Biology and Ecology, v. 343, p. 1-10, 2007.

FRACALOSSI, D.M.; ZANIBONI-FILHO, E.;MEURER, S. No rastro das espécies nativas. Panorama da Aquicultura. v.12, p.43- 49, 2002.

GOMES, L.C.; GOLOMBIESKI, J.I.; GOMES, A.R.C.; BALDISSEROTTO, B.; Biologia do jundiá Rhamdia quelen (Teleostei, Pimelodidae) Ciência Rural, v. 30, n. 1, p. 179-185, 2000.

HEMRE G.I.; MOMMSEN T.P.; KROGDAHL A. Carbohydrates in fish nutrition: effects on growth, glucose metabolism and hepatic enzymes. Aquaculture Nutrition, v.8, p.175-194, 2002.

KROGDAHL, A.; HEMRE, G-I.; MOMMSEN, T.P. Carbohydrates in fish nutrition: digestion and absorption in postlarval stages. Aquaculture Nutrition., v.11, p.103$122,2005$.

MELO, J.F.B.; LUNDSTEDT, L.M.; METÓN, I.; BAANANTE, I.V.; MORAES, G. Effects of dietary levels of protein on nitrogenous metabolism of Rhamdia quelen (Teleostei: Pimelodidae), Comparative Biochemistry and Physiology - Part A: Molecular \& Integrative Physiology, v.145, 2, p. 181-187, 2006.

PEDRON, F. Composição e gelatinização do amido na resposta biológica do jundiá (Rhamdia quelen). (Tese de Doutorado) Universidade Federal de Santa Maria, 111p., 2010 disponível em: $<$ http://cascavel.cpd.ufsm.br/tede/tde_arquivos/9/TDE-

2010-12-15T115532Z-

2972/Publico/PEDRON,\%20FABIO\%20DE\%20ARAUJ

O.pdf > . Acesso em: março de 2011.

RAWLES, S.D.; LOCHMANN, R. Effects of amylopectin/amylose starch ratio on growth, body composition and glycemic response of sunshine bass Morone chrysops $q \times$ M. saxatilis $\hat{\sigma}$. Journal of World Aquaculture Society, v.34, p.278-288, 2003.

SALHI, M.; BESSONART, M.; CHEDIAK, G.; BELLAGAMBA, M.; CARNEVIA, D. Growth, feed utilization and body composition of black catfish, Rhamdia quelen, fry fed diets containing different protein and energy levels, Aquaculture, v. 231, p.435-444, 2004.

SÁNCHEZ-MUROS, M. J., GÁRCIA-REJÓN, L., GÁRCIA-SALGUERO, L., HIGUERA, M., LUPÍANES, J. A. Long-term nutrition effects on the primary liver and kidney metabolism in rainbow trout. Adaptive response to starvation and high-protein, carbohydrate-free diet on glutamate dehydrogenase and alanine aminotransferase kinetics Biochemistry \& Cell Biology. v.30, p. 55-63, 1998.

SHIAU, S.Y. Utilization of carbohydrates in warm water fish - with particular reference to tilapia, Oreochromis niloticus $\times$ O. aureus. Aquaculture, v.151, p.79-96, 1997. 